\title{
piRNAs-the ancient hunters of genome invaders
}

\author{
Julia Verena Hartig, ${ }^{1}$ Yukihide Tomari, ${ }^{2,3,6}$ and Klaus Förstemannn ${ }^{1,4,5}$ \\ ${ }^{1}$ Gene Center of the Ludwig-Maximilians-University, D-81377 München, Germany; ${ }^{2}$ Institute of Molecular and Cellular \\ Biosciences, The University of Tokyo, Bunkyo-ku, Tokyo, 113-0032; ${ }^{3}$ PRESTO, Japan Science and Technology Agency, \\ Saitama, 332-0012, Japan; ${ }^{4}$ Munich Center for integrated Protein Science (CiPS ${ }^{\mathrm{M}}$ ), D-81377 München, Germany
}

In addition to miRNAs and siRNAs, a third small RNA silencing system has been uncovered that prevents the spreading of selfish genetic elements. Production of the Piwi-associated RNAs (piRNAs), which mediate the silencing activity in this pathway, is initiated at a few master control regions within the genome. The nature of the primary piRNA-generating transcript is still unknown, but RNA interference (RNAi)-like cleavage events are likely defining the 5 '-ends of mature piRNAs. We summarize the recent literature on piRNA biogenesis and function with an emphasis on work in Drosophila, where genetics and biochemistry have met very successfully.

In recent years the analysis of our genome has shifted from the protein coding regions to the vast expanses of genetic material in between that were initially classified simply as "junk DNA." These noncoding sequences fulfill indispensable functions; for example, to direct the assembly of specific chromatin structures and control gene expression. A series of recent findings now demonstrates that even remnant copies of selfish genetic elements, such as transposons, are put to work for the cell. They prevent the spread of active transposons with a corresponding sequence in the germline, via newly discovered small RNAs that enter a silencing pathway distinct from the RNA interference (RNAi) or microRNA (miRNA) pathways.

\section{Where did it all start?}

In their initial efforts to characterize miRNAs, Aravin et al. (2003) cloned total small RNA populations from different developmental stages of Drosophila. In addition to the expected $\sim 22$-nucleotide (nt) miRNAs, their clones yielded a distinct fraction of 24- to 29-nt-long RNAs. A peculiar finding set this class apart from miRNAs: When mapped to their genomic location, this longer species

[Keywords: Drosophila melanogaster; Stellate; piRNAs] Corresponding authors.

${ }^{5}$ E-MAIL Foerstemann@lmb.uni-muenchen.de; FAX 49-89-218076945. ${ }^{6}$ E-MAIL tomari@iam.u-tokyo.ac.jp; FAX 81-3-5841-8485.

Article is online at http://www.genesdev.org/cgi/doi/10.1101/gad.1567007. lacked a complementary star-strand nearby that can typically be found in the miRNA/miRNA* precursor hairpin structure. This already implied a novel biogenesis pathway for the 24- to 29-nt RNAs. The majority of these newly discovered RNAs corresponded to Drosophila genomic repeats or transposons, and therefore the term repeat-associated small interfering RNAs (rasiRNAs) was coined for them. At that time, several mutations had been identified in Caenorhabditis elegans that impaired RNAi and at the same time enhanced germline transposition events, suggesting that RNAi represses transposition in nematodes (Ketting and Plasterk 2000; Sijen and Plasterk 2003; Vastenhouw et al. 2003; Robert et al. 2005). In flies, however, double-stranded RNA (dsRNA) is processed into 21 -nt small interfering RNAs (siRNAs) - a distinct size class from the 24- to 29-nt rasiRNAs. Is this difference a minor detail, or indicative of a totally new small RNA biogenesis pathway?

Piwi-associated RNAs (piRNAs) are defined by their effector proteins

Small RNAs that function in RNAi or related processes are associated with proteins of the Argonaute family. In this complex, the Argonaute protein provides the biochemical activity and/or protein-protein interactions while the small RNA subunit confers sequence-specific binding to nucleic acid targets. Argonaute proteins share characteristic PAZ (Piwi, Argonaute, Zwille) and Piwi domains, and can be grouped into three families according to their sequence: the Argonaute subfamily; the Piwi subfamily; and a third, C. elegans-specific, subfamily (Yigit et al. 2006). Among the five Drosophila Argonaute proteins, Argonaute1 (Ago1) and Argonaute2 (Ago2) are involved in post-transcriptional silencing and belong to the Argonaute subfamily, while Argonaute3 (Ago3), Aubergine (Aub), and Piwi represent the Piwi subgroup. The expression of the Piwi subclass is mainly restricted to the germline (although somatic functions have been proposed as well), whereas Ago1 and Ago2 are expressed in many somatic tissues (Williams and Rubin 2002).

Several studies have now shown that Piwi subfamily proteins bind to a distinct population of small RNAs in Drosophila (Saito et al. 2006; Vagin et al. 2006; Bren- 
necke et al. 2007; Gunawardane et al. 2007), the mouse (Aravin et al. 2006; Girard et al. 2006; Grivna et al. 2006; Watanabe et al. 2006; Carmell et al. 2007), rat (Lau et al. 2006), and zebrafish (Houwing et al. 2007). Common to all of these so-called piRNAs is that the neighboring genomic sequences are devoid of a potential partner strand for the formation of a hairpin. Thus, in all species they must derive from a different type of precursor than miRNAs. Not all piRNAs are enriched for sequences from transposons and repeats: In the mouse and rat, repeats are even underrepresented, since only $\sim 17 \%$ of all piRNAs map to repetitive elements while a random distribution should yield $\sim 40 \%$, the proportion of repetitive sequences in the genome. Nonetheless, derepression of transposable elements in mice mutant for mili or miwi, two murine homologs of Drosophila piwi, and the developmental regulation of Mili-associated piRNAs suggest a function for mouse piRNAs in transposon control as well (Aravin et al. 2007; Carmell et al. 2007). The Drosophila rasiRNAs can therefore be considered as a distinct subgroup within piRNAs, and for simplicity we will refer to them as piRNAs. The importance of piwi for transposon silencing in Drosophila has also been shown genetically (Sarot et al. 2004; Kalmykova et al. 2005).

A common feature of all piRNAs is that they derive from a limited number of hot spots within the genome. This capacity to generate piRNAs was conserved in syntenic regions-for example, between mouse and rat-but the individual piRNA sequences were not (Girard et al. 2006). Perhaps piRNA hot spots are associated with or required to establish a specific chromatin structure, the importance of which may go beyond piRNA production. In the case of Drosophila, this clustering defines master regulatory loci for transposon control. For example, the flamenco locus, which controls the spread of gypsy and other mobile elements, exerts its function by developing a piRNA response against these sequences (Brennecke et al. 2007). Brennecke et al. (2007) proposed that the master regulatory loci represent a site for genetic memory of transposon exposure in the fly. Nonetheless, it is unclear why piRNA production needs to be confined to specific regions.

\section{How are piRNAs generated?}

siRNAs and miRNAs, the two most well-characterized small RNAs, are both generated through processing of double-stranded or hairpin precursors by RNase III enzymes. In flies, long dsRNA is processed by Dicer-2 (Dcr2 ), to generate $\sim 21$-nt siRNA duplexes. Primary miRNAs (pri-miRNAs) are first cleaved by Drosha in the nucleus to produce precursor miRNAs (pre-miRNAs), then exported to the cytoplasm and further processed by Dicer-1 (Dcr-1) to yield $\sim 22$-nt miRNA/miRNA * duplexes (for reviews, see Du and Zamore 2005; Kim 2005; Sontheimer 2005; Tomari and Zamore 2005). By analogy, rasiRNAs were originally thought to be processed by a Dicer-like RNase III activity (Aravin et al. 2003, 2004). However, in Drosophila, both $d c r-1$ and $d c r-2$ are dispensable for their production (Vagin et al. 2006), and in zebrafish, homozygous dicer mutant germ cells have normal levels of piRNAs (Houwing et al. 2007). How then are piRNAs produced? The large-scale sequencing efforts have shown that piRNAs from adjacent genomic locations usually have the same orientation, occasionally switching this strand bias within a piRNA generating cluster (Girard et al. 2006; Saito et al. 2006; Brennecke et al. 2007; Gunawardane et al. 2007). This anatomy suggests that piRNAs may arise from sequential processing of a longer, probably single-stranded RNA precursor.

\section{The ping-pong model}

Two teams concurrently proposed the "ping-pong" model for piRNA production (Brennecke et al. 2007; Gunawardane et al. 2007). They sequenced Piwi-, Aub-, and Ago3-associating small RNAs from Drosophila and based their model on four observations: First, Piwi and Aub bind antisense strand piRNAs, while Ago3 binds sense strand piRNAs. Second, Piwi- and Aub-interacting piRNAs often have $U$ at their 5'-end while Ago3-interacting piRNAs often have $A$ at the 10th nucleotide from their 5'-end. Third, the first $10 \mathrm{nt}$ of Ago3-interacting piRNAs can be complementary to the first 10 nt of Aubinteracting piRNAs. Fourth, Piwi, Aub, and Ago3 retain the "slicer" activity that allows them to cleave an RNA substrate across from position 10 of their bound piRNA.

Brennecke et al. (2007) and Gunawardane et al. (2007) proposed an amplification loop for piRNAs where sense piRNAs in Ago3 cleave long antisense RNA and guide the formation of the $5^{\prime}$-end of antisense piRNAs in Aub, and vice versa (Fig. 1). Since similar complementarity (although fewer cases than for Ago3 and Aub) was found between piRNAs associated with Ago3 and Piwi, the "ping-pong" model may also be applicable to Ago3 and Piwi. Moreover, a modest fraction of piRNAs from Aub and Ago3 in Drosophila (Brennecke et al. 2007) and Ziwi piRNAs in zebrafish (Houwing et al. 2007) showed a degree of complementarity that could be consistent with their biogenesis via mutual cleavage. This model, however, does not explain how the $3^{\prime}$-end of piRNAs is defined (see below). Moreover, it is enigmatic how Ago3 and Aub/Piwi are able to preferentially recognize the piRNA precursor transcripts deriving from the sense and the antisense orientation, respectively, both of which should have identical biochemical properties.

The RNA-dependent RNA polymerase (RdRP)-mediated generation of secondary siRNAs in fission yeast, worms, and plants (Cogoni and Macino 1999; Dalmay et al. 2000; Mourrain et al. 2000; Sijen and Kooter 2000; Smardon et al. 2000) serves to strengthen and sustain an RNAi response. However, there is no apparent RdRP activity in flies and mammals (Schwarz et al. 2002). Is the piRNA-generating loop an analogous, although mechanistically unrelated, amplification step that operates in the germline? Unlike RdRP-mediated amplification, the need for mutual complementarity in the ping-pong model keeps the production confined to one pair of piRNAs, preventing piRNA generation from spreading or "rolling" along a primary transcript. 


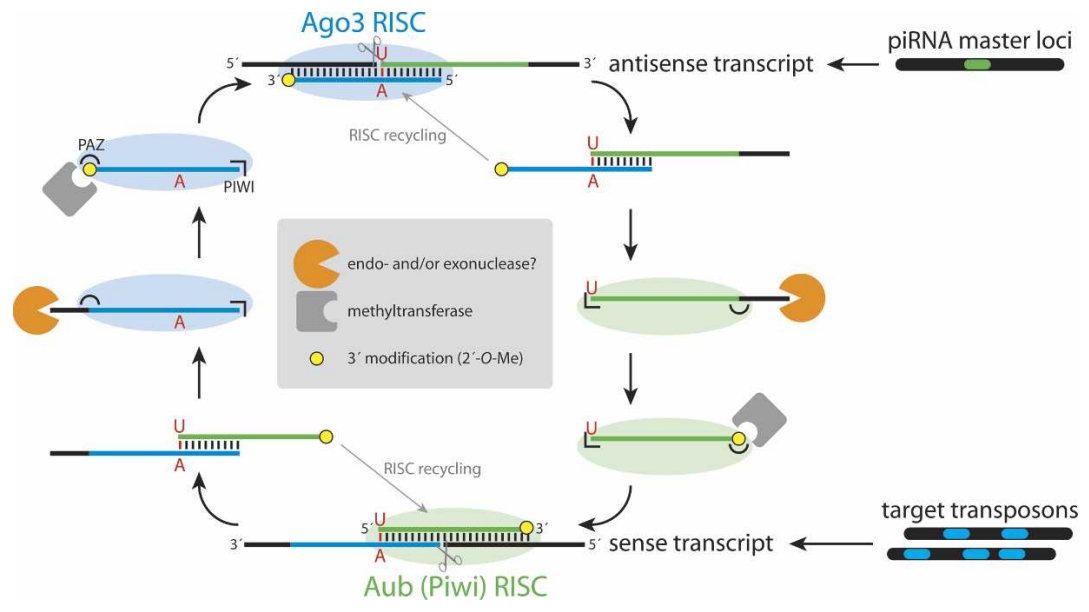

Figure 1. The ping-pong model for piRNA biogenesis. (Bottom) Sense transcripts from transposons - the kind that need to be destroyedare cleaved by Piwi or Aub RISC loaded with a piRNA guide. The cleaved transcript is not merely degraded but used to program Ago3 RISC. (Top) This complex in turn cleaves the antisense transcripts that originate from the master control loci. Again, the cleaved RNA serves to program Piwi or Aub RISC. Thus, sense and antisense transcripts fuel an amplification cycle in which the 5 '-ends of piRNAs are defined by RISC cleavage. Presumably, the 3'ends are shortened by an endonuclease and/or exonuclease to the size that fits the distance between PAZ and Piwi domains. The $3^{\prime}$-end is subsequently 2'-O-Me-modified by a methyltransferase, called Pimet/DmHen1 in Drosophila.
An important question nonetheless remains openthe ping-pong model can explain how piRNA production is sustained as long as a pre-existing pool of piRNAs is fueled with transcripts, but it gives no indication of how a new ping-pong circle can be initiated. In theory, any RNA polymerase such as RNA polymerase II or even primase could produce a piRNA precursor molecule (Bateman and $\mathrm{Wu}$ 2007). siRNA-mediated heterochromatin formation depends on RNA polymerase II in fission yeast and RNA polymerase IV in plants (Djupedal et al. 2005; Onodera et al. 2005; Schramke et al. 2005; Huettel et al. 2006), but a dedicated RNA polymerase for the transcription at piRNA hotspots remains to be identified. Once generated, how is this putative trigger molecule then processed de novo into piRNAs? All we know at this point is that an initiation pathway exists: The identification of piRNAs directed against the P-element, a DNA transposon that colonized the Drosophila population only during the last 50 years, suggests that de novo synthesis of piRNAs occurs when the target element becomes associated with one of the master regulatory loci (Brennecke et al. 2007).

\section{3'-end formation of piRNAs}

Although no crystal structures of animal Piwi subfamily proteins have been solved yet, analysis of Argonaute family proteins shows that the Piwi domain and PAZ domain bind to the $5^{\prime}$-phosphate and $3^{\prime}$-end of the guide strand, respectively (for review, see Hall 2005; Tolia and Joshua-Tor 2007). siRNAs, when programmed in vitro (Schwarz et al. 2002) or transfected in cultured cells (Reynolds et al. 2006), are most active at a length of $\sim 21$ $\mathrm{nt}$, indicating that the Piwi and PAZ domains define a length limit for the siRNA guide strand. It is possible that the distance between Piwi and PAZ domains may be slightly longer in Piwi subfamily proteins than in Argonaute subfamily proteins to accommodate the size of piRNAs. Thus, a newly formed piRNA 5 '-end may be anchored in the Piwi domain of an acceptor protein, then endonucleases and/or exonucleases shorten the $3^{\prime}$-end to the most suitable length for binding to the PAZ domain. Two candidate nucleases for piRNA maturation have been identified in Drosophila. In the absence of either squash or zucchini, transposons are no longer repressed and no piRNAs are detectable (Pane et al. 2007).

\section{3'-end modification of piRNAs}

Like miRNAs and siRNAs, Drosophila piRNAs can be ligated at their $3^{\prime}$-end, indicating that at least one hydroxyl group is present at this end. In contrast to miRNAs, piRNAs were resistant to oxidation of vicinal diols on the ribose sugar and subsequent $\beta$-elimination (Vagin et al. 2006). This proved that one terminal hydroxyl group is blocked. Subsequently, a 2'-O-Methyl $\left(2^{\prime}-O-M e\right)$ modification was identified at the $3^{\prime}$-ends of mouse piRNAs (Kirino and Mourelatos 2007; Ohara et al. 2007), bull, and Drosophila piRNAs (Horwich et al. 2007; Saito et al. 2007). Rat piRNAs were similarly shown to be 2'-O-Me-modified, and Houwing et al. (2007) presumed that zebrafish piRNAs are as well. It is thus tempting to speculate that all piRNAs have a 2 '-O-Me modification at their 3 '-end. This might serve to discriminate piRNAs from siRNAs and miRNAs. However, recent reports show that siRNAs derived from transgenically expressed long hairpin constructs are $3^{\prime}$-modified in flies (Horwich et al. 2007; Pelisson et al. 2007). Moreover, even exogenous siRNAs can be readily modified in vitro using Drosophila extracts (Horwich et al. 2007). Whether siRNAs are also modified in mammals remains to be determined. In contrast, miRNAs are unmodified in all animals reported. In plants, miRNAs, transgene or repeat-derived siRNAs and transacting siRNAs (tasiRNAs) are all 2'-O-Me-modified by the HEN1 methyltransferase, and purified HEN1 can methylate synthetic miRNA/miRNA ${ }^{\star}$ and siRNA duplexes, but not single-stranded small RNA (Li et al. 2005; Yu et al. 2005). Loss of hen 1 causes an unusual 3' polyuridylation of small RNAs and lowers the steady-state level of some of 
them, resulting in modest developmental defects (Li et al. 2005). A Drosophila homolog of HEN1, called Pimet/ DmHen1, appends the 2'-O-Me modification onto piRNAs (Horwich et al. 2007; Saito et al. 2007). pimet/ hen 1 encodes a single-strand-specific methyltransferase that lacks the dsRNA-binding domain of plant HEN1; piRNAs isolated from pimet/hen1 mutant ovaries are unmodified. Recombinant Pimet/DmHen 1 protein can bind to Aub, Piwi, and Ago3 complexes isolated from pimet/hen 1 mutant ovaries and methylate the piRNAs within Aub complexes. This suggests that the 3 '-end resection of piRNA precursors precedes methylation. In contrast, Pimet/DmHen 1 does not bind to Agol or methylate miRNA/miRNA* duplexes or single-stranded miRNAs bound to Ago1. However, both Ago2-loaded siRNAs and an endogenous miRNA that is partially loaded into Ago2 are 2'-O-Me-modified by Pimet/ DmHen 1 after a mature RISC with the single-stranded small RNA has been formed. The slightly shorter length of piRNAs isolated from pimet/hen1 mutant flies suggests that modification of piRNAs and siRNAs might protect them from further trimming by exonucleases (Horwich et al. 2007). Since pimet/hen1 mutant flies are viable and fertile, the presence of a 2 '-O-Me modification does not appear to be essential for piRNA function (Saito et al. 2007). Nonetheless, at least the HetA retrotransposon becomes derepressed in pimet/hen1 mutant flies (Horwich et al. 2007).

\section{Mysterious helicases}

In flies, armitage (armi) and spindle-E (spn-E) are required for piRNA production and/or stability (Savitsky et al. 2006; Vagin et al. 2006). These genes were originally identified because mutant flies show defects in embryonic axis specification (Pare and Suter 2000; Martin et al. 2003; Cook et al. 2004). While little is known about the subcellular localization of Spn-E, Armi protein is cytoplasmic and associates with the microtubule cytoskeleton in egg chambers (Cook et al. 2004). Ovary extracts from armi mutant flies also show defects in siRNA-directed RISC assembly (Tomari et al. 2004). What could a helicase contribute to the biogenesis of Piwi complexes? One can think of several possibilities, but none of them is supported by experimental evidence at this point. First, a helicase may be required to dissociate the slicer products during piRNA ping-pong. Second, maybe the piRNA trigger molecule is nonetheless dsRNA (e.g., resulting from bidirectional transcription), but RNA helicases are recruited to unwind the duplex, thereby prevent dicing, and rather channel one of the strands into piRNA biogenesis. Third, helicases can also remove proteins from nucleic acids or remodel an RNA-protein complex (for reviews, see Jankowsky and Bowers 2006; Linder 2006), and this is essential for piRNA biogenesis from transcripts of master regulatory loci. Finally, RNA helicases may participate in $3^{\prime}$-end resection by removing secondary structures so that exonucleases can chew the piRNA down to the stump that is protected by the Piwi subfamily protein.

\section{Activation of a DNA damage checkpoint in flies with piRNA pathway mutations}

The axis specification defects in the piRNA pathway genes spn-E, $a u b$, and armi mutant ovaries have recently been linked to persistent DNA-damage signaling because they are suppressed by mutations in mnk and mei41, the Drosophila homologs of Chk2 and ATR, respectively (Chen et al. 2007; Klattenhoff et al. 2007). Mutations in piRNA pathway genes lead to accumulation of phosphorylated $\gamma-\mathrm{H} 2 \mathrm{Av}$ foci, a marker for DNA damage. While inactivation of mnk and mei-41 suppressed the consequences of persistent DNA damage signaling, transposons remained derepressed and $\gamma-\mathrm{H} 2 \mathrm{Av}$ foci were still accumulating in the double mutant animals (Klattenhoff et al. 2007). Although the studies do not provide direct evidence, a straightforward interpretation is that abnormal DNA structures (such as double-strand breaks or integration intermediates) induced by rampant transposition activate the DNA damage signaling cascade.

\section{Stellate silencing depends on piRNAs}

The Stellate locus, a repetitive protein-coding gene located on the X chromosome, is silenced by the Su(Ste) locus on the Y chromosome (for review, see Gvozdev et al. 2000). Originally, this was thought to occur in an RNAi-like process initiated by dsRNA resulting from bidirectional transcription of the Su(Ste) locus (Aravin et al. 2001). The corresponding small RNAs had later been classified by Aravin et al. (2003) among the rasiRNAs. Stellate silencing shares many of the hallmarks of piRNA action, such as the accumulation of 24- to 29-ntlong antisense RNAs, whose biogenesis depends on $a u b$ and the putative RNA helicases armi and spn-E, but is independent of piwi (Vagin et al. 2006). The Stellate silencing system is thus related to piRNA silencing.

\section{Transmission of piRNAs}

How a piRNA response can be generated de novo is so far unclear. In Drosophila, crosses between strains that carry a certain transposable element and strains that do not harbor it in their genome can result in mobilization of this transposon in the germline of F1 animals, leading to severely impaired fertility. This phenomenon, called hybrid dysgenesis, occurs only in the progeny of an unexposed (naïve) mother with an exposed father but not vice versa (dysgenic vs. nondysgenic orientation of the cross). In a study with Drosophila virilis, piRNAs corresponding to such a transposon could be found solely in the offspring from the nondysgenic cross, suggesting that only mothers can transmit piRNA-mediated transposon control (Blumenstiel and Hartl 2005). Thus, de novo generation of piRNAs may be limited to gametogenesis and require maternal imprinting.

\section{Is unpaired DNA important for piRNA generation?}

In the fungus Neurospora crassa, any piece of DNA that is not paired to a corresponding sequence on the homolo- 
gous chromosome will become silenced during meiosis in a process called meiotic silencing of unpaired DNA (MSUD) (Shiu et al. 2001; Shiu and Metzenberg 2002). This resembles piRNA function not only through its timing (meiotic prophase), but also because it depends on the Argonaute protein Sms-2 (Lee et al. 2003). In principle, repetitive sequences and tandem copies of transposons may pair in several registers and create stretches of unpaired DNA. Could unpaired DNA be the trigger for piRNA production? Drosophila balancer chromosomes carry multiple inversions and are used to prevent meiotic pairing and recombination. If unpaired DNA were sufficient to induce piRNA production, balancer chromosomes should result in massive piRNA production, possibly competing with transposon-derived piRNAs for effector proteins. Yet, crosses involving balancer chromosomes do not normally result in loss of transposon control. The correlation of only maternally inherited piRNAs with suppression of hybrid dysgenesis (Blumenstiel and Hartl 2005) also indicates that piRNA generation is more complex. Lack of a partner in meiosis may therefore not be sufficient to initiate de novo production of piRNAs in Drosophila, but it is possible that unpaired DNA helps to sustain the piRNA response by generating an unusual transcript that fuels the amplification loop.

\section{Are C. elegans 21U-RNAs related to piRNAs?}

The intense sequencing efforts from several laboratories-the total number of published sequence reads approaches 700,000 - have made the nematode C. elegans the organism with the most extensively charted repertoire of small RNAs (Lau et al. 2001; Lee and Ambros 2001; Ambros et al. 2003; Lim et al. 2003; Ruby et al. 2006; Pak and Fire 2007). However, no bona fide piRNAs have been identified so far. In one study, $\sim 10 \%$ of the sequenced small RNAs belong to a class of 21-nt-long RNAs with a very strong preference for uridine as their 5 '-most base (Ruby et al. 2006), called 21U-RNAs. They share several features of piRNAs, such as the clustering in discrete genomic regions, no enrichment for homology with known transcripts, a modified 3 '-end and no indication that they derive from a double-stranded precursor RNA. Like mammalian piRNA clusters, the $21 \mathrm{U}$ RNA generating loci are conserved between C. elegans and Caenorhabditis briggsae, but the sequences of the individual 21U-RNAs are not (Ruby et al. 2006).

On the other hand, most 21U-RNAs share an upstream sequence motif that is conserved between $C$. elegans and $C$. briggsae. This motif could either represent a promotor for the transcription of $21 \mathrm{U}-\mathrm{RNAs}$, or it could be a conserved processing signal that defines the 5 '-end of the mature 21U-RNA. No such motif has been observed for piRNAs. The ping-pong model for piRNA biogenesis postulates that the $5^{\prime}$-ends of piRNAs are generated via reciprocal cleavage directed by two distinct populations of piRNAs. The only other C. elegans small RNA class with a detectable nucleotide preference is a 26-nt-long species with guanine at the $5^{\prime}$-end. While G could, in principle, base-pair with $U$ in RNA, the posi- tion at the $5^{\prime}$-end in both cases excludes biogenesis through mutual cleavage (Ruby et al. 2006).

\section{Conclusion}

A new small RNA silencing pathway has begun to reveal some of its secrets. However, we still do not know how a new piRNA response is initiated. Also, it is unclear why some regions in our genome are so uniquely poised to produce piRNAs. Genetic experiments and large-scale sequencing have been extremely informative, but the next breakthrough may well come from biochemical experiments that recapitulate the loading of Piwi subfamily proteins, and maybe even the biogenesis of piRNAs, in vitro.

\section{Acknowledgments}

We apologize to all colleagues whose work could not be discussed due to space limitations. In particular, we regret that the roles of Piwi subfamily proteins in somatic cells and in heterochromatin formation had to be left out.

\section{References}

Ambros, V., Lee, R.C., Lavanway, A., Williams, P.T., and Jewell, D. 2003. MicroRNAs and other tiny endogenous RNAs in $C$. elegans. Curr. Biol. 13: 807-818.

Aravin, A.A., Naumova, N.M., Tulin, A.V., Vagin, V.V., Rozovsky, Y.M., and Gvozdev, V.A. 2001. Double-stranded RNA-mediated silencing of genomic tandem repeats and transposable elements in the $D$. melanogaster germline. Curr. Biol. 11: 1017-1027.

Aravin, A.A., Lagos-Quintana, M., Yalcin, A., Zavolan, M., Marks, D., Snyder, B., Gaasterland, T., Meyer, J., and Tuschl, T. 2003. The small RNA profile during Drosophila melanogaster development. Dev. Cell 5: 337-350.

Aravin, A.A., Klenov, M.S., Vagin, V.V., Bantignies, F., Cavalli, G., and Gvozdev, V.A. 2004. Dissection of a natural RNA silencing process in the Drosophila melanogaster germ line. Mol. Cell. Biol. 24: 6742-6750.

Aravin, A., Gaidatzis, D., Pfeffer, S., Lagos-Quintana, M., Landgraf, P., Iovino, N., Morris, P., Brownstein, M.J., KuramochiMiyagawa, S., Nakano, T., et al. 2006. A novel class of small RNAs bind to MILI protein in mouse testes. Nature 442: 203-207.

Aravin, A.A., Sachidanandam, R., Girard, A., Fejes-Toth, K., and Hannon, G.J. 2007. Developmentally regulated piRNA clusters implicate MILI in transposon control. Science 316: 744 747.

Bateman, J.R. and Wu, C.T. 2007. DNA replication and models for the origin of piRNAs. Bioessays 29: 382-385.

Blumenstiel, J.P. and Hartl, D.L. 2005. Evidence for maternally transmitted small interfering RNA in the repression of transposition in Drosophila virilis. Proc. Natl. Acad. Sci. 102: 15965-15970.

Brennecke, J., Aravin, A.A., Stark, A., Dus, M., Kellis, M., Sachidanandam, R., and Hannon, G.J. 2007. Discrete small RNA-generating loci as master regulators of transposon activity in Drosophila. Cell 128: 1089-1103.

Carmell, M.A., Girard, A., van de Kant, H.J., Bourc'his, D., Bestor, T.H., de Rooij, D.G., and Hannon, G.J. 2007. MIWI2 is essential for spermatogenesis and repression of transposons 
in the mouse male germline. Dev. Cell 12: 503-514.

Chen, Y., Pane, A., and Schupbach, T. 2007. Cutoff and aubergine mutations result in retrotransposon upregulation and checkpoint activation in Drosophila. Curr. Biol. 17: 637642.

Cogoni, C. and Macino, G. 1999. Homology-dependent gene silencing in plants and fungi: A number of variations on the same theme. Curr. Opin. Microbiol. 2: 657-662.

Cook, H.A., Koppetsch, B.S., Wu, J., and Theurkauf, W.E. 2004. The Drosophila SDE3 homolog armitage is required for oskar mRNA silencing and embryonic axis specification. Cell 116: 817-829.

Dalmay, T., Hamilton, A., Rudd, S., Angell, S., and Baulcombe, D.C. 2000. An RNA-dependent RNA polymerase gene in Arabidopsis is required for posttranscriptional gene silencing mediated by a transgene but not by a virus. Cell 101: $543-$ 553.

Djupedal, I., Portoso, M., Spahr, H., Bonilla, C., Gustafsson, C.M., Allshire, R.C., and Ekwall, K. 2005. RNA Pol II subunit Rpb7 promotes centromeric transcription and RNAidirected chromatin silencing. Genes \& Dev. 19: 2301-2306.

Du, T. and Zamore, P.D. 2005. microPrimer: The biogenesis and function of microRNA. Development 132: 4645-4652.

Girard, A., Sachidanandam, R., Hannon, G.J., and Carmell, M.A. 2006. A germline-specific class of small RNAs binds mammalian Piwi proteins. Nature 442: 199-202.

Grivna, S.T., Pyhtila, B., and Lin, H. 2006. MIWI associates with translational machinery and PIWI-interacting RNAs (piRNAs) in regulating spermatogenesis. Proc. Natl. Acad. Sci. 103: 13415-13420.

Gunawardane, L.S., Saito, K., Nishida, K.M., Miyoshi, K., Kawamura, Y., Nagami, T., Siomi, H., and Siomi, M.C. 2007. A slicer-mediated mechanism for repeat-associated siRNA $5^{\prime}$ end formation in Drosophila. Science 315: 1587-1590.

Gvozdev, V.A., Kogan, G.L., Tulin, A.A., Aravin, A.A., Naumova, N.M., and Shevelyov, Y.Y. 2000. Paralogous stellate and $\mathrm{Su}(\mathrm{Ste})$ repeats: Evolution and ability to silence a reporter gene. Genetica 109: 131-140.

Hall, T.M. 2005. Structure and function of argonaute proteins. Structure 13: 1403-1408.

Horwich, M.D., Li, C., Matranga, C., Vagin, V., Farley, G., Wang, P., and Zamore, P.D. 2007. The Drosophila RNA methyltransferase, DmHen1, modifies both piRNAs and single-stranded siRNAs in RISC and is required for silencing selfish genetic elements in the germ line. Curr. Biol. (in press).

Houwing, S., Kamminga, L.M., Berezikov, E., Cronembold, D., Girard, A., van den Elst, H., Filippov, D.V., Blaser, H., Raz, E., Moens, C.B., et al. 2007. A role for Piwi and piRNAs in germ cell maintenance and transposon silencing in zebrafish. Cell 129: 69-82.

Huettel, B., Kanno, T., Daxinger, L., Aufsatz, W., Matzke, A.J., and Matzke, M. 2006. Endogenous targets of RNA-directed DNA methylation and Pol IV in Arabidopsis. EMBO J. 25: 2828-2836.

Jankowsky, E. and Bowers, H. 2006. Remodeling of ribonucleoprotein complexes with DExH/D RNA helicases. Nucleic Acids Res. 34: 4181-4188.

Kalmykova, A.I., Klenov, M.S., and Gvozdev, V.A. 2005. Argonaute protein PIWI controls mobilization of retrotransposons in the Drosophila male germline. Nucleic Acids Res. 33: 2052-2059.

Ketting, R.F. and Plasterk, R.H. 2000. A genetic link between co-suppression and RNA interference in C. elegans. Nature 404: 296-298.

Kim, V.N. 2005. Small RNAs: Classification, biogenesis, and function. Mol. Cells 19: 1-15.

Kirino, Y. and Mourelatos, Z. 2007. Mouse Piwi-interacting RNAs are 2'-O-methylated at their $3^{\prime}$ termini. Nat. Struct. Mol. Biol. 14: 347-348.

Klattenhoff, C., Bratu, D.P., McGinnis-Schultz, N., Koppetsch, B.S., Cook, H.A., and Theurkauf, W.E. 2007. Drosophila rasiRNA pathway mutations disrupt embryonic axis specification through activation of an ATR/Chk2 DNA damage response. Dev. Cell 12: 45-55.

Lau, N.C., Lim, L.P., Weinstein, E.G., and Bartel, D.P. 2001. An abundant class of tiny RNAs with probable regulatory roles in Caenorhabditis elegans. Science 294: 858-862.

Lau, N.C., Seto, A.G., Kim, J., Kuramochi-Miyagawa, S., Nakano, T., Bartel, D.P., and Kingston, R.E. 2006. Characterization of the piRNA complex from rat testes. Science 313: 363-367.

Lee, R.C. and Ambros, V. 2001. An extensive class of small RNAs in Caenorhabditis elegans. Science 294: 862-864.

Lee, D.W., Pratt, R.J., McLaughlin, M., and Aramayo, R. 2003. An argonaute-like protein is required for meiotic silencing. Genetics 164: 821-828.

Li, J., Yang, Z., Yu, B., Liu, J., and Chen, X. 2005. Methylation protects miRNAs and siRNAs from a 3 '-end uridylation activity in Arabidopsis. Curr. Biol. 15: 1501-1507.

Lim, L.P., Lau, N.C., Weinstein, E.G., Abdelhakim, A., Yekta, S., Rhoades, M.W., Burge, C.B., and Bartel, D.P. 2003. The microRNAs of Caenorhabditis elegans. Genes \& Dev. 17: 991-1008.

Linder, P. 2006. Dead-box proteins: A family affair-Active and passive players in RNP-remodeling. Nucleic Acids Res. 34: 4168-4180.

Martin, S.G., Leclerc, V., Smith-Litiere, K., and St Johnston, D. 2003. The identification of novel genes required for Drosophila anteroposterior axis formation in a germline clone screen using GFP-Staufen. Development 130: 4201-4215.

Mourrain, P., Beclin, C., and Vaucheret, H. 2000. Are gene silencing mutants good tools for reliable transgene expression or reliable silencing of endogenous genes in plants? Genet. Eng. (N.Y.) 22: 155-170.

Ohara, T., Sakaguchi, Y., Suzuki, T., Ueda, H., Miyauchi, K., and Suzuki, T. 2007. The 3' termini of mouse Piwi-interacting RNAs are 2'-O-methylated. Nat. Struct. Mol. Biol. 14: 349-350.

Onodera, Y., Haag, J.R., Ream, T., Nunes, P.C., Pontes, O., and Pikaard, C.S. 2005. Plant nuclear RNA polymerase IV mediates siRNA and DNA methylation-dependent heterochromatin formation. Cell 120: 613-622.

Pak, J. and Fire, A. 2007. Distinct populations of primary and secondary effectors during RNAi in C. elegans. Science 315: 241-244.

Pane, A., Wehr, K., and Schüpbach, T. 2007. zucchini and squash encode two putative nucleases required for rasiRNA production in the Drosophila germline. Developmental Cell 12: $851-863$.

Pare, C. and Suter, B. 2000. Subcellular localization of Bic$\mathrm{D}:: \mathrm{GFP}$ is linked to an asymmetric oocyte nucleus. I. Cell Sci. 113: 2119-2127.

Pelisson, A., Sarot, E., Payen-Groschene, G., and Bucheton, A. 2007. A novel repeat-associated small interfering RNA-mediated silencing pathway downregulates complementary sense gypsy transcripts in somatic cells of the Drosophila ovary. J. Virol. 81: 1951-1960.

Reynolds, A., Anderson, E.M., Vermeulen, A., Fedorov, Y., Robinson, K., Leake, D., Karpilow, J., Marshall, W.S., and Khvorova, A. 2006. Induction of the interferon response by siRNA is cell type- and duplex length-dependent. RNA 12: 988-993. 
Robert, V.J., Sijen, T., van Wolfswinkel, J., and Plasterk, R.H. 2005. Chromatin and RNAi factors protect the C. elegans germline against repetitive sequences. Genes \& Dev. 19: 782-787.

Ruby, J.G., Jan, C., Player, C., Axtell, M.J., Lee, W., Nusbaum, C., Ge, H., and Bartel, D.P. 2006. Large-scale sequencing reveals 21U-RNAs and additional microRNAs and endogenous siRNAs in C. elegans. Cell 127: 1193-1207.

Saito, K., Nishida, K.M., Mori, T., Kawamura, Y., Miyoshi, K., Nagami, T., Siomi, H., and Siomi, M.C. 2006. Specific association of Piwi with rasiRNAs derived from retrotransposon and heterochromatic regions in the Drosophila genome. Genes \& Dev. 20: 2214-2222.

Saito, K., Sakaguchi, Y., Suzuki, T., Suzuki, T., Siomi, H., and Siomi, M.C. 2007. Pimet, the Drosophila homolog of HEN1, mediates 2'-O-methylation of Piwi-interacting RNAs at their 3' ends. Genes \& Dev. 21: 1603-1608.

Sarot, E., Payen-Groschene, G., Bucheton, A., and Pelisson, A. 2004. Evidence for a piwi-dependent RNA silencing of the gypsy endogenous retrovirus by the Drosophila melanogaster flamenco gene. Genetics 166: 1313-1321.

Savitsky, M., Kwon, D., Georgiev, P., Kalmykova, A., and Gvozdev, V. 2006. Telomere elongation is under the control of the RNAi-based mechanism in the Drosophila germline. Genes \& Dev. 20: 345-354.

Schramke, V., Sheedy, D.M., Denli, A.M., Bonila, C., Ekwall, K., Hannon, G.J., and Allshire, R.C. 2005. RNA-interferencedirected chromatin modification coupled to RNA polymerase II transcription. Nature 435: 1275-1279.

Schwarz, D.S., Hutvagner, G., Haley, B., and Zamore, P.D. 2002. Evidence that siRNAs function as guides, not primers, in the Drosophila and human RNAi pathways. Mol. Cell 10: $537-$ 548.

Shiu, P.K. and Metzenberg, R.L. 2002. Meiotic silencing by unpaired DNA: Properties, regulation and suppression. Genetics 161: 1483-1495.

Shiu, P.K., Raju, N.B., Zickler, D., and Metzenberg, R.L. 2001. Meiotic silencing by unpaired DNA. Cell 107: 905-916.

Sijen, T. and Kooter, J.M. 2000. Post-transcriptional gene-silencing: RNAs on the attack or on the defense? Bioessays 22: 520-531.

Sijen, T. and Plasterk, R.H. 2003. Transposon silencing in the Caenorhabditis elegans germ line by natural RNAi. Nature 426: 310-314.

Smardon, A., Spoerke, J.M., Stacey, S.C., Klein, M.E., Mackin, N., and Maine, E.M. 2000. EGO-1 is related to RNA-directed RNA polymerase and functions in germ-line development and RNA interference in C. elegans. Curr. Biol. 10: 169-178.

Sontheimer, E.J. 2005. Assembly and function of RNA silencing complexes. Nat. Rev. Mol. Cell Biol. 6: 127-138.

Tolia, N.H. and Joshua-Tor, L. 2007. Slicer and the argonautes. Nat. Chem. Biol. 3: 36-43.

Tomari, Y. and Zamore, P.D. 2005. Perspective: Machines for RNAi. Genes \& Dev. 19: 517-529.

Tomari, Y., Du, T., Haley, B., Schwarz, D.S., Bennett, R., Cook, H.A., Koppetsch, B.S., Theurkauf, W.E., and Zamore, P.D. 2004. RISC assembly defects in the Drosophila RNAi mutant armitage. Cell 116: 831-841.

Vagin, V.V., Sigova, A., Li, C., Seitz, H., Gvozdev, V., and Zamore, P.D. 2006. A distinct small RNA pathway silences selfish genetic elements in the germline. Science 313: 320324.

Vastenhouw, N.L., Fischer, S.E., Robert, V.J., Thijssen, K.L., Fraser, A.G., Kamath, R.S., Ahringer, J., and Plasterk, R.H. 2003. A genome-wide screen identifies 27 genes involved in transposon silencing in C. elegans. Curr. Biol. 13: 1311-1316.
Watanabe, T., Takeda, A., Tsukiyama, T., Mise, K., Okuno, T. Sasaki, H., Minami, N., and Imai, H. 2006. Identification and characterization of two novel classes of small RNAs in the mouse germline: Retrotransposon-derived siRNAs in oocytes and germline small RNAs in testes. Genes \& Dev. 20: 1732-1743.

Williams, R.W. and Rubin, G.M. 2002. ARGONAUTE1 is required for efficient RNA interference in Drosophila embryos. Proc. Nat1. Acad. Sci. 99: 6889-6894.

Yigit, E., Batista, P.J., Bei, Y., Pang, K.M., Chen, C.C., Tolia, N.H., Joshua-Tor, L., Mitani, S., Simard, M.J., and Mello, C.C. 2006. Analysis of the C. elegans Argonaute family reveals that distinct Argonautes act sequentially during RNAi. Cell 127: 747-757.

Yu, B., Yang, Z., Li, J., Minakhina, S., Yang, M., Padgett, R.W., Steward, R., and Chen, X. 2005. Methylation as a crucial step in plant microRNA biogenesis. Science 307: 932-935. 


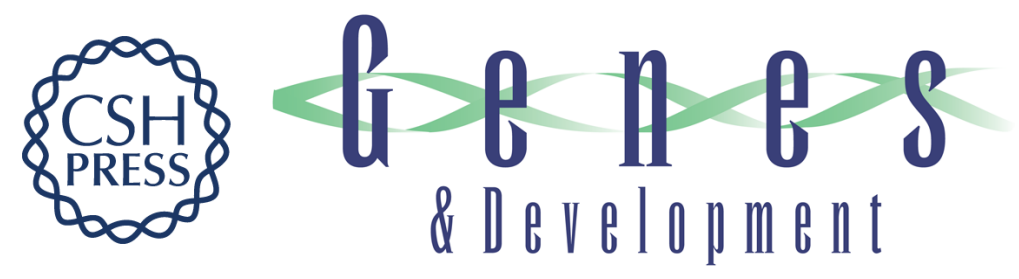

\section{piRNAs--the ancient hunters of genome invaders}

Julia Verena Hartig, Yukihide Tomari and Klaus Förstemann

Genes Dev. 2007, 21:

Access the most recent version at doi:10.1101/gad.1567007

References This article cites 68 articles, 28 of which can be accessed free at: http://genesdev.cshlp.org/content/21/14/1707.full.html\#ref-list-1

License

Email Alerting Receive free email alerts when new articles cite this article - sign up in the box at the top Service right corner of the article or click here.

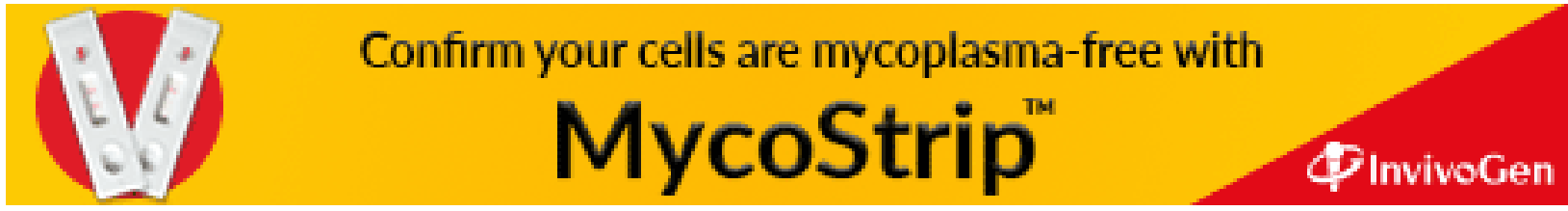

